\title{
Effect of 2-mercaptoethanol as capping agent on ZnS nanoparticles: structural and optical characterization
}

\author{
Abbas Rahdar
}

\begin{abstract}
In this work, we report the effect of a capping agent on the structural and optical properties of nanocrystalline ZnS particles, which have been synthesized by co-precipitation method. The structural properties of ZnS nanoparticles have been characterized by X-ray diffraction (XRD) analysis. The XRD patterns show a hexagonal structure in the nanoparticles. The mean crystallite size calculated from the XRD patterns has been found to be in the range of 1.80 to $2.45 \mathrm{~nm}$ with the increase in molar concentration of the capping agent. Absorption spectra have been obtained using a UV-vis spectrophotometer to find the optical direct band gap. We also found that optical band gap $\left(E_{\mathrm{g}}\right)$ increases with the increase in molar concentration of the capping agent. This behavior is related to size quantization effect due to the small size of the particles.
\end{abstract}

Keywords: ZnS nanoparticles, Chemical co-precipitation method, Capping agent, Optical band gap

\section{Background}

Semiconductor nanocrystals represent a class of materials that have hybrid molecular and bulk properties. They have attracted much attention over the past few years because of their novel properties which originate from quantum confinement effect [1-4]. Quantum confinement effect modifies the electronic structure of the nanocrystals when the sizes of the nanoparticles are comparable to that of the Bohr excitonic radius of those materials. When the particle radius falls below the excitonic Bohr radius, the band gap energy is widened, leading to a blueshift in the band gap, emission spectra, etc. On the other hand, the surface states will play a more important role in the nanoparticles, due to their large surface-to-volume ratio with a decrease in particle size (surface effects). In the case of semiconductor nanoparticles, radiative or nonradiative recombination of an exciton at the surface states becomes dominant in its optical properties with a decrease of particle size. Therefore, the decay of an exciton at the surface states will influence the qualities of the material for an optoelectronic device. These size-dependent optical properties have many potential applications in

Correspondence: a.rahdar@uoz.ac.ir

Department of Physics, Faculty of Science, University of Zabol, Zabol 98615538, Iran the areas of solar energy conversion, light-emitting devices, chemical/biological sensors, and photocatalysis [5-9].

Wide band gap II-VI semiconductors are expected to be the novel materials for the optoelectronic devices. $\mathrm{ZnS}$, which is an important member of this family, has been extensively investigated as it has numerous applications to its credit. ZnS has been used widely as an important phosphor for photoluminescence, electroluminescence, and cathodoluminescence devices due to its better chemical stability compared to other chalcogenides such as ZnSe. In optoelectronics, it finds use as light-emitting diode, reflector, dielectric filter, and window material. The synthesis of $\mathrm{ZnS}$ remains a topic of interest for researchers, as new synthetic routes are being explored to get a single phase material via an economically and technically viable method. In the present paper, chemical method has been used to synthesize the $\mathrm{ZnS}$ nanoparticles. In the present paper, $\mathrm{ZnS}$ nanoparticles are synthesized by using mercaptoethanol as capping agent. This paper is organized as follows: The structural and optical properties of synthesized nanoparticles are presented in the 'Results and discussion' section in detail, followed by a 'Conclusion' section. In the 'Methods' section, we give a description of materials and synthesis method of $\mathrm{ZnS}$ nanoparticles with different molar concentrations of the capping agent.

\section{勿}

(c) 2013 Rahdar; licensee Springer. This is an Open Access article distributed under the terms of the Creative Commons Attribution License (http://creativecommons.org/licenses/by/2.0), which permits unrestricted use, distribution, and reproduction in any medium, provided the original work is properly cited. 


\section{Results and discussion}

\section{Structural characterization}

The X-ray diffraction (XRD) patterns of the prepared $\mathrm{ZnS}$ nanoparticles with different molar concentrations of the capping agent $\left(\mathrm{HOCH}_{2} \mathrm{CH}_{2} \mathrm{SH}\right)$ are shown in Figure 1. All of the crystalline Bragg peaks in the XRD pattern ((111), (220), and (311) planes) are in good agreement with the diffraction data of a hexagonal structure with cell parameters $a=3.800 \AA$ and $c=6.230 \AA$ from the JCPDS card. Furthermore, the peak broadening in the XRD patterns clearly indicates the formation of $\mathrm{ZnS}$ nanocrystals with a very small size.

The peak broadening at a lower angle is more meaningful for the calculation of particle size. The mean crystallite size $(D)$ of nanoparticles was also estimated using the Scherrer formula (Scherrer 1918) using (111) reflection from the XRD pattern as follows:

$$
D=\frac{0.9 \lambda}{B \cos \theta}
$$

where $\lambda, B$, and $\theta$ are the X-ray wavelength of the radiation used $\left(\mathrm{K}_{\alpha}(\mathrm{Cu})=0.154056 \mathrm{~nm}\right)$, the full width at half maximum of the diffraction peak, and the Bragg diffraction angle, respectively.

The values of mean crystallite size obtained from XRD for different molar concentrations of the capping agent are listed in Table 1.

\section{Optical characterization}

The absorption spectra of the different samples are shown in Figure 2. The absorption edge is observed in the range of 324 to $270 \mathrm{~nm}$, which is blueshifted compared to bulk ZnS. As the molar concentration of the capping agent increases, the absorption edge shifts to a lower wavelength compared to $\mathrm{ZnS}(\mathrm{A})$. This blueshift of the absorption edges for different-sized nanocrystals is related to the size decrease of particles and is attributed to the quantum confinement limit reaching of nanoparticles. The quantum confinement effect is expected for semiconducting nanoparticles, and
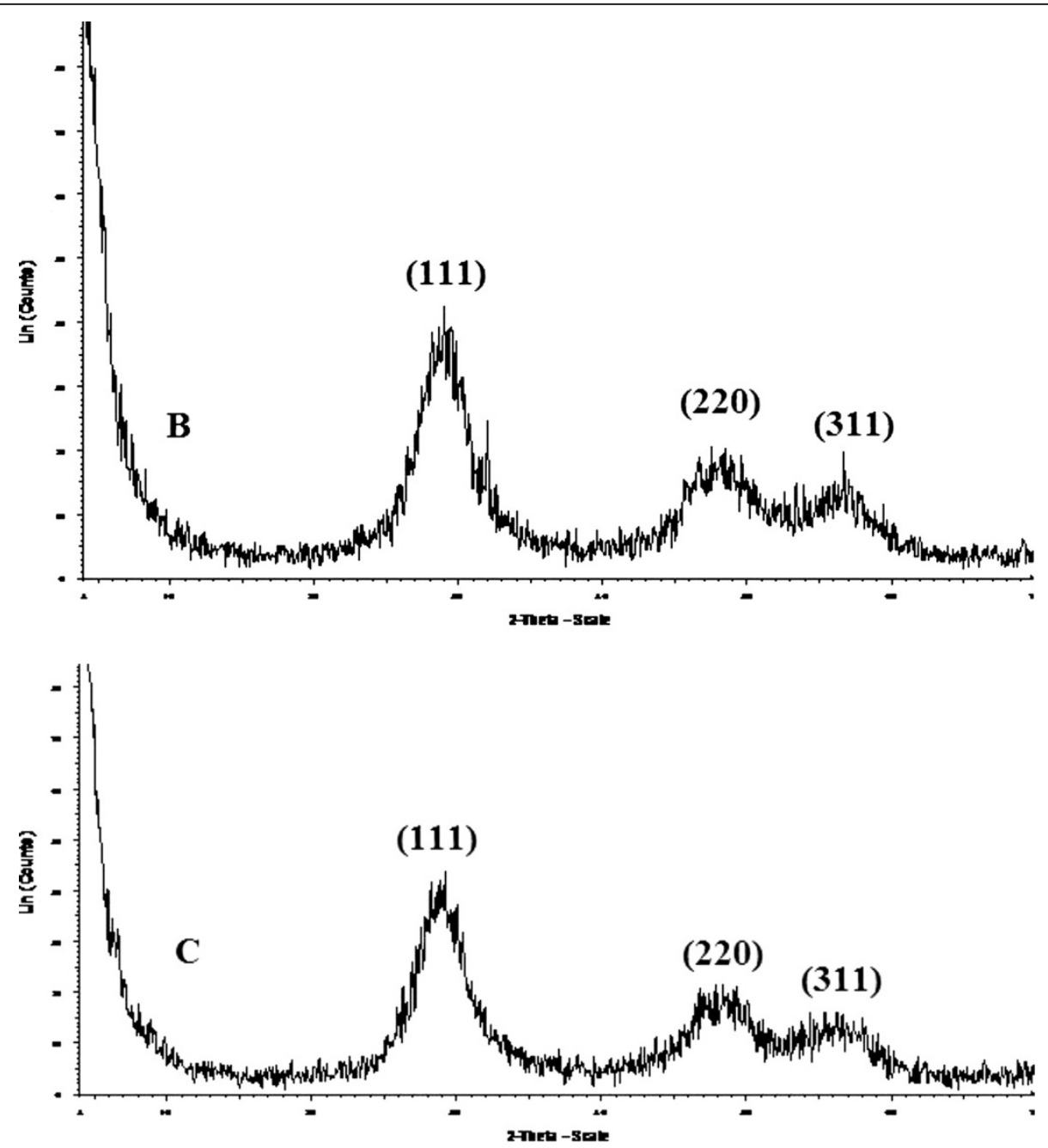

Figure 1 XRD patterns of ZnS nanoparticles. With different molar (M) concentrations of capping agent: $0.1 \mathrm{M}(\mathrm{B})$ and $0.3 \mathrm{M}(\mathrm{C})$. 
Table 1 Mean crystallite size and optical band gap variation of $\mathrm{ZnS}$ nanoparticles

\begin{tabular}{lccc}
\hline Sample & $\begin{array}{c}\text { Molar concentration } \\
\text { of capping agent }\end{array}$ & $\begin{array}{c}\text { Mean crystallite } \\
\text { size }(\mathbf{n m})\end{array}$ & $\begin{array}{c}\text { Optical band } \\
\text { gap } \boldsymbol{E}_{\mathbf{g}}(\mathbf{e V})\end{array}$ \\
\hline ZnS (A) & 0.0 & 2.45 & 3.83 \\
ZnS (B) & 0.1 & 2.38 & 4.27 \\
ZnS (C) & 0.3 & 2.22 & 4.49 \\
ZnS (D) & 0.5 & 1.80 & 4.59 \\
\hline
\end{tabular}

the absorption edge will be shifted to a higher energy when the particle size decreases $[10,11]$.

The obtained direct optical band gap values for different samples are shown in Table 1. It is necessary to mention that the optical direct band gap values of the $\mathrm{ZnS}$ nanoparticles were determined using Tauc's relation $[12,13]$ :

$$
\alpha h v=\alpha_{0}\left(h v-E_{g}\right)^{1 / 2},
$$

where $\mathrm{h} v, \alpha_{\mathrm{o}}$, and $E_{\mathrm{g}}$ are the photon energy, a constant, and optical band gap of the nanoparticles, respectively. Absorption coefficient $(\alpha)$ of the powders at different wavelengths can be calculated from the absorption spectra. Finally, the values of $E_{\mathrm{g}}$ were determined using extrapolations of the linear regions of the plot of $(\alpha h v)^{2}$ versus $h v$.

As seen in Table 1, the values of optical band gap ' $E_{\mathrm{g}}$ ' increase with the increase in molar concentration of the capping agent, and therefore, the decrease in particle size as mentioned earlier is due to the quantum confinement effect. Also, the variation of optical band gap with particle size is shown in Figure 3. As illustrated in Figure 3, the optical band gap values of nanoparticles have changed from 3.83 to $4.59 \mathrm{eV}$ by decreasing the particle sizes. The increase in band gap with increase in molar concentration of the capping agent is attributed to size quantization effect due to the small size of the particles [14].

These semiconductor nanocrystals were then subjected to transmission electron microscopy (TEM; JEOL JEM3010, JEOL Ltd., Tokyo, Japan) for characterization. Figure 4

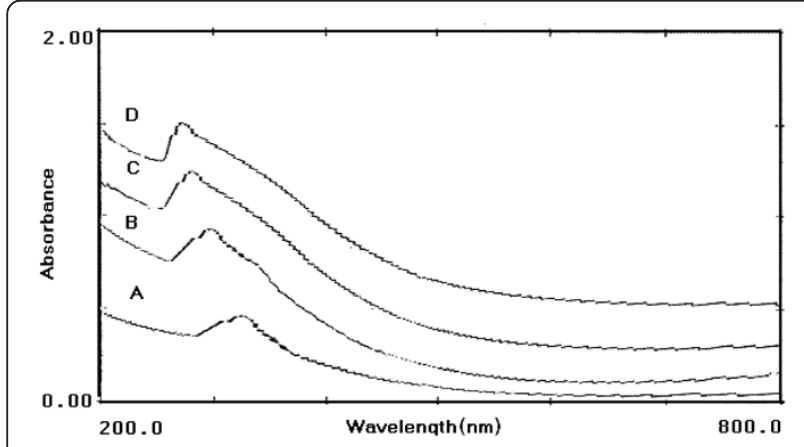

Figure 2 Absorption spectra of different samples of $\mathrm{ZnS}$ nanoparticles. $0 \mathrm{M}(\mathbf{A}), 0.1 \mathrm{M}(\mathbf{B}), 0.3 \mathrm{M} \mathrm{(C)}$, and $0.5 \mathrm{M}(\mathbf{D})$.

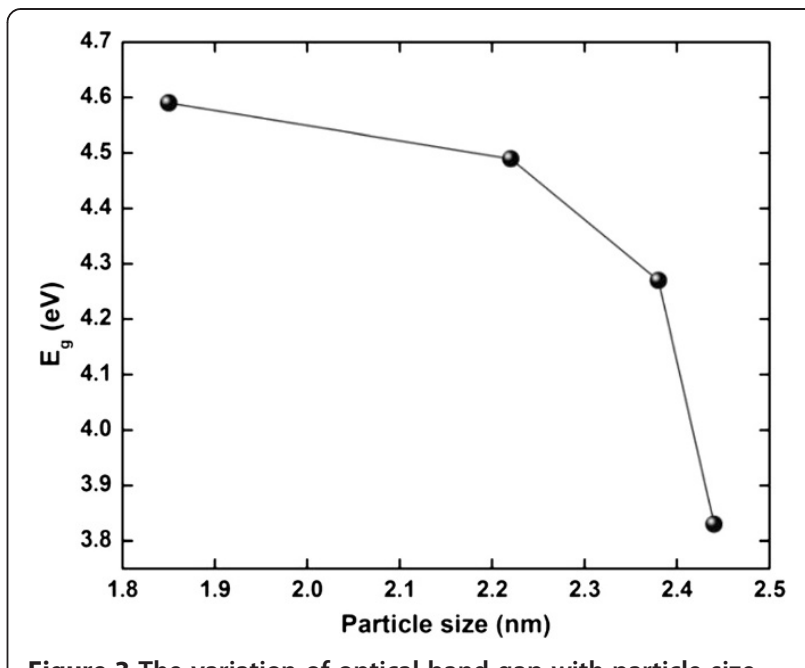

Figure 3 The variation of optical band gap with particle size.

shows the TEM image of ME-capped ZnS semiconductor nanocrystals.

\section{Relation particle size with chemical reaction rate}

Chemical reaction rate directly affects the time evolution of the number of nuclei, which determines both nucleation and growth process. First, the influence on nucleation is obvious: nucleation is faster when the chemical reaction is faster. Second, growth will be strongly influenced by the nuclei number which already formed at a given time. A great number of nucleation favor a fast autocatalytic growth, giving rise to a large number of small particles. Chemical reaction controls this kind of growth, in which the autocatalytic growth is faster when the chemical reaction is faster. However, in nanoparticle formation, there is another contribution to the growth molecules on the surface of a small particle which will tend to diffuse through the solution and add to the surface of a larger particle (growth by ripening). A slow chemical reaction

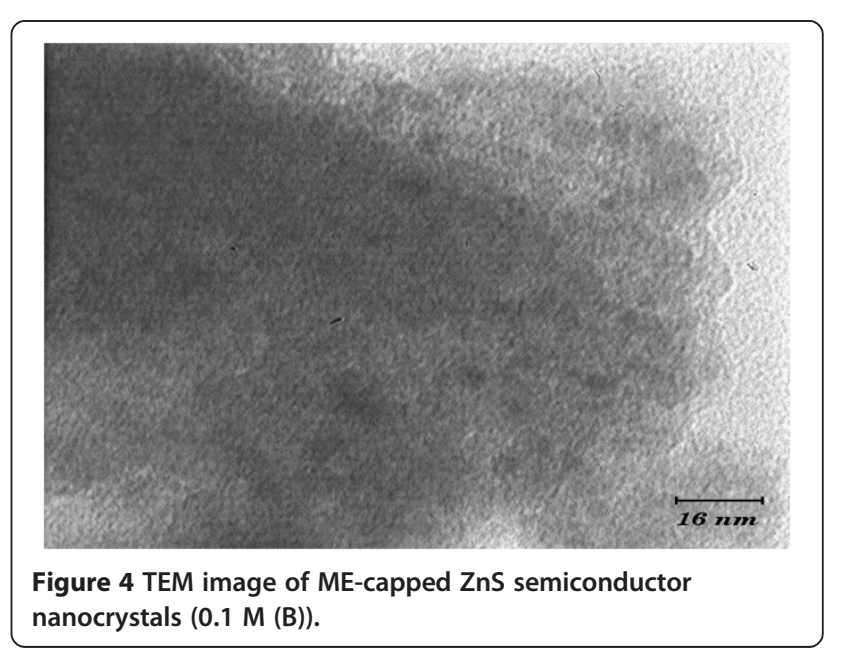


favors continuous nuclei, keeping always a certain number of nuclei in the system. As a result, growth by ripening can take place during the whole process. This fact explains the bigger particle size obtained from a slow reaction. One can conclude that a slow chemical reaction rate is associated with a more important ripening contribution to the growth. A high number of nuclei are still forming at this stage when the reaction is slow at the same time; some particles have already grown to the final value of size. This means that in this case (slow reaction rate), nucleation and growth take place simultaneously. This overlapping of nucleation and growth processes, which is more pronounced as the chemical reaction is slower, leads to larger nanoparticle sizes [15].

Rate of reaction depends on the molar concentration of the reactant solution and increases with the increase in molar concentration of the reactant solution. In the present study, the molar concentration of the capping agent varies from 0 to $0.5 \mathrm{M}$; the reaction rate is highest for the $0.5 \mathrm{M}$ solution, and hence, the particle size obtained is smallest for the $0.5 \mathrm{M}$ solution as compared to other materials in the series, which is in consistent with the above made argument.

\section{Conclusions}

It is possible to produce different-sized $\mathrm{ZnS}$ nanoparticles using a simple chemical method using different molar concentrations of the capping agent. XRD and optical band gap data have been obtained to confirm the nanosize of these materials. It is also observed that the particle size depends on the molar concentration of the capping agent. A decrease in formation rate of nanoparticles gives rise to a larger final particle size for all the studied synthesis conditions. As the particle size depends on the molar concentration of the doping agent, a decrease in the size of particle is observed with the increase of molar concentration of the capping agent. The mean crystallite size range of particles was between 1.85 and $2.44 \mathrm{~nm}$, depending on molar concentration of the capping agent. The optical band gap values of $\mathrm{ZnS}$ nanoparticles have changed from 3.83 to 4.59 $\mathrm{eV}$ by increasing the molar concentration of the capping agent. These values exhibit a blueshift in $E_{\mathrm{g}}$ which is related to the size decrease of the particles and to the quantum confinement limit reaching of nanoparticles.

Considering these results, the chemical co-precipitation method using 2-mercaptoethanol as a capping agent is very efficient for the preparation of $\mathrm{ZnS}$ nanoparticles in order to control the particle size and also for modern optoelectronic technology and other industrial applications.

\section{Methods}

Materials

Zinc chloride $\left(\mathrm{ZnCl}_{2}\right)$ and sodium sulfide $\left(\mathrm{Na}_{2} \mathrm{~S}\right)$ as starting materials, 2-mercaptoethanol $\left(\mathrm{HOCH}_{2} \mathrm{CH}_{2} \mathrm{SH}\right)$ as

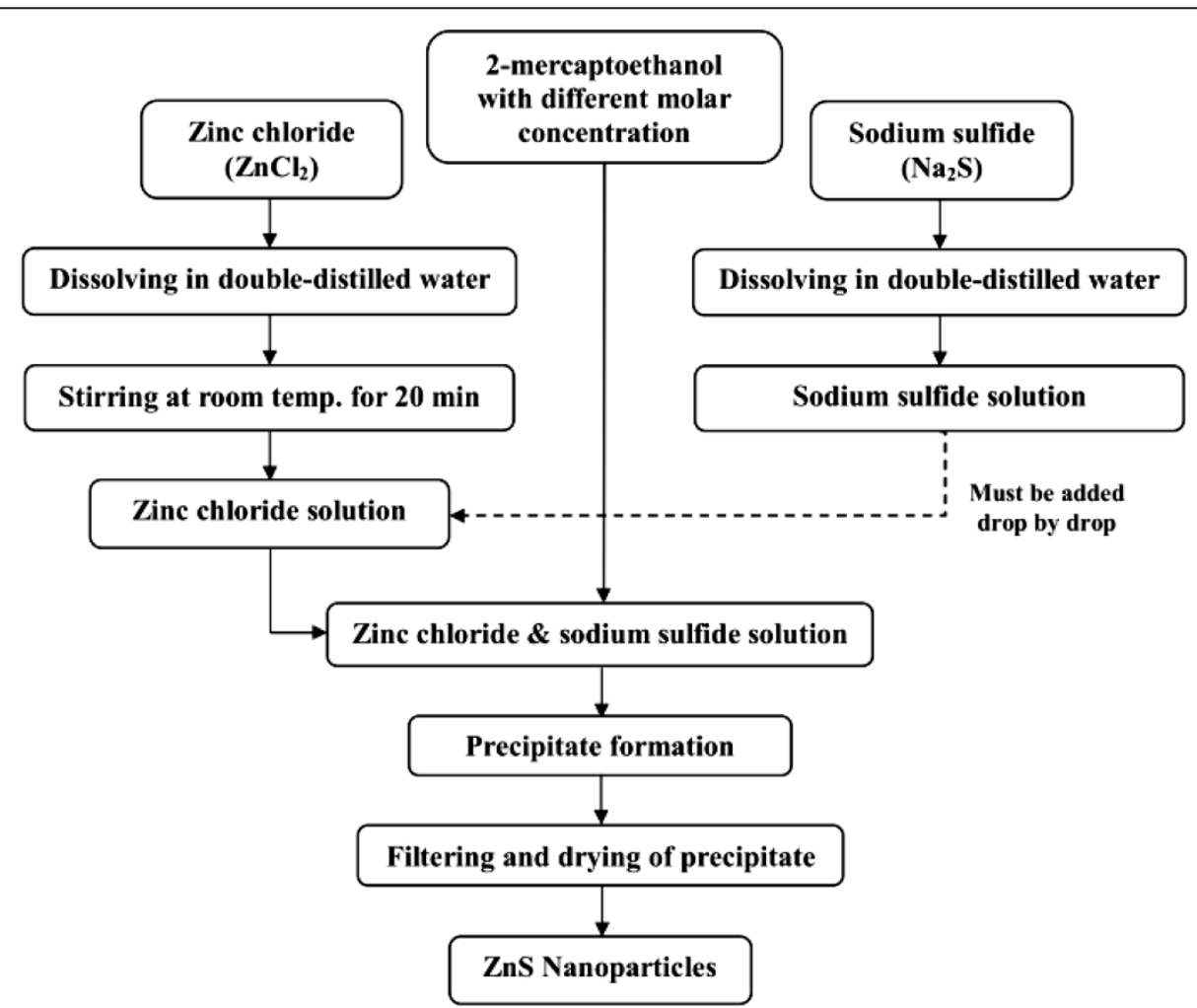

Figure 5 Flow chart of the preparation ZnS nanoparticles by chemical co-precipitation method. 
a capping agent for the control particle size, and doubledistilled water as dispersing solvent were used to prepare ZnS nanoparticles.

\section{Synthesis of ZnS nanoparticles by co-precipitation method} The ZnS nanoparticles were synthesized using the chemical co-precipitation method as follows. First, $\mathrm{ZnCl}_{2}$ was dissolved in double-distilled water $(0.1 \mathrm{M})$, and then, the obtained molar solution was stirred for $20 \mathrm{~min}$ at room temperature to achieve complete dissolution. Sodium sulfide $\left(\mathrm{Na}_{2} \mathrm{~S}\right)$ was also dissolved in double-distilled water separately as per molar concentration. Afterwards, first, sodium sulfide solution was added drop by drop to the zinc chloride solution, and then, an appropriate amount of 2-mercaptoethanol as a capping agent was added to the reaction medium to control the particle size of $\mathrm{ZnS}$. As a result of this, the white precipitate of the $\mathrm{ZnS}$ nanoparticles is formed slowly in the solution. In the final step, the obtained precipitate was filtered and dried at room temperature to remove both water and organic capping and other byproducts which formed during the reaction process. After sufficient drying, the precipitate was crushed to fine powder with the use of mortar and pestle. It is mentioned that the synthesis was done by passing nitrogen gas.

For the study of the effect of the capping agent on structural and optical properties of $\mathrm{ZnS}$ nanoparticles, different samples of nanoparticles have been obtained by changing the molar concentration of the capping agent, namely $\mathrm{ZnS}(\mathrm{A}), \mathrm{ZnS}(\mathrm{B}), \mathrm{ZnS}(\mathrm{C})$ and $\mathrm{ZnS}(\mathrm{D})$, as the amount of molar concentration of the capping agent used in the preparation is $0,0.1,0.3$ and $0.5 \mathrm{M}$, respectively. The synthesis process of $\mathrm{ZnS}$ nanoparticles by the co-precipitation method is summarized in a flow chart shown in Figure 5.

\section{Powder characterization}

The XRD patterns of $\mathrm{ZnS}$ nanoparticles were recorded using a Bruker system (Bruker Optik GmbH, Ettlingen, Germany) using $\mathrm{CuK}_{\alpha}$ radiation $(\lambda=0.154056 \mathrm{~nm})$ with $2 \theta$ ranging from $5^{\circ}$ to $70^{\circ}$. The optical absorption spectra of nanoparticles were measured using a USB-2000 UV-vis spectrophotometer (Ocean Optics, Inc., Dunedin, FL, USA). Therefore, the obtained nanopowders have been suspended in glycerol using a magnetic stirrer, and their optical absorption spectra have been recorded at room temperature over the range of 200 to $800 \mathrm{~nm}$ to determine the optical band gap values.

\section{Competing interests}

The author has no competing interests.

\section{Acknowledgmen}

The author would like to thank Mr. A. Rahdar, Mr. R. Hakimi-Pooya, Mrs. M. Asudeh, Mr. H. Rahdar, and Mrs. Heidari Mokarrar for their support and assistance with this project.
Received: 26 December 2012 Accepted: 10 March 2013

Published: 15 April 2013

\section{References}

1. Rossetti, R, Ellison, JL, Gibson, JM, Brus, LE: Size effects in the excited electronic states of small colloidal CdS crystallites. J. Chem Phys. 80 , 4464 (1984)

2. Sang, W, Qian, Y, Min, J, Li, D, Wang, L, Shi, W, Liu, Y: Microstructural and optical properties of ZnS:Cu nanocrystals prepared by an ion complex transformation method. Solid State Commun. 121, 475-478 (2002)

3. Prabhu, RR, Abdul Khadar, M: Characterization of chemically synthesized CdS nanoparticles. Pramana- J. Phys. 5, 801 (2005)

4. Wageh, S, Ling, ZS, Xu-Rong, X: Growth and optical properties of colloidal ZnS nanoparticles. J. Cryst. Growth 255, 332-337 (2003)

5. Rajeswar, K, Tacconi, NR, Chenthamarakshan, CR: Semiconductor-based composite materials: preparation, properties, and performance. Chem. Mater. 13, 2765 (2001)

6. Alivisatos, AP: Semiconductor clusters, nanocrystals, and quantum dots. Science 271, 933-937 (1996)

7. Anderson, MA, Gorer, S, Penner, RM: A hybrid electrochemical/chemical synthesis of supported, luminescent cadmium sulfide nanocrystals. J. Phys. Chem. B 101, 5895 (1997)

8. Henshaw, G, Parkin, IP, Shaw, G: Convenient low-energy synthesis of metal sulfides and selenides; $\mathrm{PbE}, \mathrm{Ag}_{2} \mathrm{E}, \mathrm{ZnE}, \mathrm{CdE}(\mathrm{E}=\mathrm{S}$, Se). Chem. Commun. 10, 1095-1096 (1996)

9. Hirai, T, Bando, Y, Komasawa, I: Immobilization of CdS nanoparticles formed in reverse micelles onto alumina particles and their photocatalytic properties. J. Phys. Chem. B 106, 8967-8970 (2002)

10. Zhu, H, Yang, D, Yu, G, Zhang, H, Yao, K: A simple hydrothermal route for synthesizing $\mathrm{SnO}_{2}$ quantum dots. Nanotechnology 17, 2386 (2006)

11. Sarhaddi, R, Shahtahmasebi, N, Rezaee Rokn-Abadi, M, Bagheri-Mohagheghi, MM: Effect of post-annealing temperature on nano-structure and energy band gap of indium tin oxide (ITO) nano-particles synthesized by polymerizing-complexing sol-gel method. Physica E 43, 452-457 (2010)

12. Tauc, J: Optical Properties of Solids. Academic Press, New York (1966)

13. Liu, CM, Zu, XT, Wei, QM, Wang, LM: Fabrication and characterization of wire-like $\mathrm{SnO}_{2}$. J. Phys. D: Appl. Phys. 39, 2494 (2006)

14. Amaranatha Reddy, D, Divya, A, Murali, G, Vijayalakshmi, RP, Reddy, BK: Synthesis and optical properties of $\mathrm{Cr}$ doped $\mathrm{ZnS}$ nanoparticles capped by 2-mercaptoethanol. Physica B 406, 1944-1949 (2011)

15. de Dios, M, Barroso, F, Tojo, C, Blanco, MC, Lopez-Quintela, MA: Effects of the reaction rate on the size control of nanoparticles synthesized in microemulsions. Colloids and Surfaces A: Physicochem. Eng. Aspects 83, 270 (2005)

doi:10.1186/2193-8865-3-10

Cite this article as: Rahdar: Effect of 2-mercaptoethanol as capping agent on ZnS nanoparticles: structural and optical characterization. Journal Of Nanostructure in Chemistry 2013 3:10.

\section{Submit your manuscript to a SpringerOpen ${ }^{\circ}$ journal and benefit from:}

- Convenient online submission

- Rigorous peer review

- Immediate publication on acceptance

- Open access: articles freely available online

- High visibility within the field

- Retaining the copyright to your article

Submit your next manuscript at $>$ springeropen.com 